\title{
Analisis Pola Pengajaran Guru SMP di Kabupaten Pulau Morotai Terhadap Siswa Lamban Belajar
}

\author{
*Balqis Husain ${ }^{1}$, Saifudin S. Adam², Ibrahim Ibrahim ${ }^{3}$ \\ ${ }^{1,2}$ Universitas Pasifik Morotai \\ ${ }^{3}$ Universitas Muhammadiyah Sorong \\ *balqishusain.bh@gmail.com \\ Saifudinsadam@gmail.com \\ Ibrahim080988@gmail.com
}

\begin{abstract}
Abstrak
Penelitian ini bertujuan untuk mengetahui pola pngajaran yang diterapkan guru SMP di Kabupaten Pulau Morotai terhadap siswa lamban belajar. Sekolah yang dipilih untuk mewakili penelitian ini adalah MTS N 1. Pulau Morotai, SMP N 14 Morotai, MTS Muhammadiyah 1 Pulau Morotai, dan SMP N 2 Pulau Morotai. Penelitian ini dilaksanakan pada bulan Februari 2019 sampai bulan November 2019. Peneliti menetapkan subjek dalam penelitian ini adalah siswa lamban belajar yang tersebar di 4 sekolah serta wali kelas, guru mata pelajaran dan guru BK di 5 sekolah. Teknik pengambilan sampel pada penelitian ini menggunakan teknik purposive sampling hal ini berdasarkan subjek penelitian yaitu siswa lamban belajar. Penelitian ini menggunakan pendekatan qualitative. Metode penelitian yang digunakan adalah descriptive analisis. Teknik pengumpulan data melalui wawancara dan observasi. Hasil Penelitian menunjukkan bahwa kebutuhan siswa lamban belajar yang menempuh pendidikan di sekolah umum belum sepenuhnya terpenuhi dan belum mendapatkan perhatian serius dari pelaku pendidikan. Belum adanya adaptasi kurikulum yang menyesuaikan dengan kebutuhan siswa lamban belajar sehingga kebutuhan siswa lamban belajar tidak terakomodasi dengan baik. penggunaan kurikulum di sekolah umum untuk siswa lamban belajar membutuhkan beberapa penyesuaian beberapa aspek program pembelajaran. Aspek program pembelajaran mencakup cara penyajian, cara respon siswa, keterlibatannya dalam belajar serta penambahan strategi, metode maupun teknik pembelajaran.
\end{abstract}

Kata Kunci: Pola pengajaran, siswa lamban belajar

\begin{abstract}
This research aims to determine the pattern of speech applied by junior high school teachers in Morotai Island district to students slowly learning. The school chosen to represent this research is MTS N 1. Morotai Island, SMP N 14 Morotai, MTS Muhammadiyah 1 Morotai Island, and SMP N 2 Morotai Island. The study was conducted in February 2019 to November 2019. Researchers set the subject in this study is sluggish student learning spread across 4 schools as well as caregivers, teacher subjects and BK teachers in 5 schools. The sampling techniques in this study used purposive sampling techniques based on the research subject of students ' slow learning. This research uses the qualitative approach. The research method used is descriptive analysis. Data collection techniques through interviews and observations. The results showed that the students 'slow learning needs that attended public schools have not been fully fulfilled and have not received any serious attention from educational actors. The lack of a curriculum adaptation that adapts to the needs of slow learning students so that the students 'sluggish learning needs are not well--accommodation. The use of curricula in public schools for slowly learning students requires some adjustments to some aspects of the learning program. Aspects of the learning program include the way of presentation, how students respond, their involvement in learning and the addition of strategies, methods and learning techniques.
\end{abstract}

Keywords: pattern teaching, students slow learning 


\section{PENDAHULUAN}

Sejak paradigma inklusi mulai merebak di dunia pendidikan pada tahun 2000, perhatian masyarakat terhadap dunia pendidikan mulai meningkat. Munculnya paradigma inklusi didorong oleh fenomena untuk menegakkan hak asasi manusia dan demokrasi, serta adanya tuntutan dimana pendidikan sekolah mampu mengakomodasi proses belajar siswa baik dari segi kondisi maupun variasi level yang berbeda. Dengan kata lain pendidikan harus memenuhi segala aspek baik dari segi multikultur, berkeadilan/ equity, serta kesetaraan/ equality (Mumpuniarti, 2011: 2). Tak jarang di jumpai sebagian besar siswa yang mengalami permasalahan belajar di sekolah umum salah satunya merupakan siswa yang mengelami keterbelakangan dalam belajar atau siswa lamban belajar (slow learners). Menurut Sari dan Samawi (2014:140) siswa lamban belajar adalah siswa yang memiliki keterbatasan ketika harus berpikir abstrak dan simbolis.

Kemampuan berpikir mereka jauh berbeda dengan siswa pada umumnya. Mereka juga tidak mampu menyelesaikan tugas-tugas sekolah dengan baik. Seperti yang diungkapkan Bala dan Rao (2004: 119) kebanyakan dari siswa tersebut mempunyai skor IQ antara 76 dan 89 . Chaucan (2011:282-283) menjelaskan secara rinci bahwa ciri siswa lamban belajar tidak dapat diidentifikasikan melalui fisik akan tetapi dapat di identifikasi pada saat proses pembelajaran berlangsung, adapun ciri khusus siswa lamban belajar sbb; memiliki keterbatasan menginterpretasikan data; memiliki kebiasaan yang rendah, keterbatasan berfikir secara abstrak, kemampuan akademik rendah, sulit dalam berkonsentrasi; memiliki tingkat percaya diri yang rendah; menglami kesulitan dalam menulis; cenderung memiliki emosi yang tidak stabil.

Menurut Palupi \& Darmahusni (2017:79-80), ciri khusus siswa lamban belajar yaitu cenderung bersifat pasif dalam belajar, memiliki keterbatasan berfikir secara abstrak, memiliki kesulitan dalam berkonsentrasi, tidak percaya diri dan sulitnya berkonsentrasi. Disamping itu, karakteristik siswa lamban belajar tidak dapat diidentifikasi secara fisik, akan tetapi hanya dapat diidentifikasi pada saat proses belajar mengajar berlangsung, yang pada akhirnya penerapan system pembelajaran di kelas diperlakukan sama dengan siswa pada umumnya baik pada penyelesaian soal latihan, penyampaian materi, teknik maupun strategi pengajaran. Tantangan inilah yang harus disikapi secara bijak oleh para tenaga pengajar di Kab Pulau Morotai, mengingat siswa lamban belajar di Kabupaten Pulau morotai secarah penuh diberikan peluang mengikuti pembelajaran di sekolah-sekolah formal pada umumnya. Tugas guru dalam mengajar siswa lamban belajar yaitu 
memahami karakteristik siswa itu sendiri, mengawal perkembangan kemajuan siswa serta menciptakan suasana mempelajaran yang mampu merangsang pemahaman siswa (Husain: 2019) . Salah satu tindakan untuk mengakomodasi kebutuhan belajar siswa lamban belajar (slow learner) adalah sebagai bentuk dukungan terhadap paradigma inklusi di sekolah. Pembelajaran yang diusahakan oleh guru ialah sebuah upaya mengkondisikan siswa belajar lamban belajar (Slow Learner) sesuai dengan kebutuhan belajar mereka. Mereka membutuhkan sajian dari guru dengan berbagai pendekatan untuk memediasi kesulitan di dalam belajar konsep abstrak. Kondisi itu perlu diciptakan guru dengan mengembangkan disain rancangan pembelajaran yang sesuai dengan kebutuhan belajar siswa lamban belajar (slow learner).

\section{METODE}

Penelitian ini dilaksanakan di Kecamatan Morotai Selatan dan Kecamatan Morotai Timur, Kab. Pulau Morotai. Sekolah yang dipilih untuk mewakili penelitian ini adalah MTS N 1. Pulau Morotai, SMP N 14 Morotai, MTS Muhammadiyah 1 Pulau Morotai, dan SMP N 2 Pulau Morotai. Penelitian ini dilaksanakan pada bulan Februari 2019 sampai bulan November 2019. Peneliti menetapkan subjek dalam penelitian ini adalah siswa lamban belajar yang tersebar di 4 sekolah serta wali kelas, guru mata pelajaran dan guru BK di 5 sekolah. Teknik pengambilan sampel pada penelitian ini menggunakan teknik purposive sampling hal ini berdasarkan subjek penelitian yaitu siswa lamban belajar. Penelitian ini menggunakan pendekatan qualitative.

Metode penelitian yang digunakanmadalah descriptive analisis. Teknik pengumpulan data melalui wawancara dan observasi. Wawancara dan observasi dilakukan untuk mengetahui sebaran siswa lamban belajar yang terdapat di 4 SMP sederajat di Kab Pulau Morotai serta untuk mengetahui perlakuan pembelajaran yang diterapkan oleh guru di SMP sederajat terhadap siswa lamban belajar. Teknik pengumpulan data dalam penelitian ini menggunakan teknik wawancara dan observasi.

a. Wawancara: Wawancara mendalam dilakukan pada guru mata pelajaran, guru BK, serta wali kelas, hal ini bertujuan untuk mengidentifikasi siswa lamban belajar dalam kelas serta untuk mengetahui perlakuan pembelajaran yang diberikan guru kepada siswa lamban belajar. 
b. Observasi: Observasi dilakukan pada guru mata pelajaran dan siswa lamban belajar pada saat proses pembelajaran dikelas berlangsung. Teknik observasi bertujuan untuk mengetahui pola pengajaran yang diberikan oleh guru mata pelajaran pada siswa lamban belajar.

\section{HASIL DAN PEMBAHASAN}

\section{a. Klasifikasi Siswa Lamban Belajar}

Berdasarkan hasil wawancara yang dilakukan terhadap guru Wali Kelas, guru Mata Pelajaran, maupun guru Bimbingan Konseling pada 4 sekolah Menengah Pertama (SMP/MTS) di Kab Pulau Morotai, ditemukan bahwa terdapat siswa lamban belajar yang mengenyam pendidikan di sekolah formal pada umumnya tersebar baik di kelas satu, dua, dan tiga. Adapun sebaran siswa lamban belajar dapat dilihat pada tabel dibawah ini;

Tabel 3. Klasifikasi Siswa Lamban Belajar

\begin{tabular}{ccccc}
\hline No & Nama Sekolah & $\mathrm{JK}$ & $\mathrm{Ni}$ & $\mathrm{N}$ \\
\hline 1. & SMP N 2 Pulau Morotai & $\mathrm{L}$ & 3 & 10 \\
\cline { 3 - 4 } & & $\mathrm{P}$ & 7 & \\
\hline 2. & SMP N 14 Morotai & $\mathrm{L}$ & 2 & 11 \\
\cline { 3 - 4 } & & $\mathrm{P}$ & 9 & \\
\hline 3. & MTS N 1 Pulau Morotai & $\mathrm{L}$ & 6 & 9 \\
\cline { 3 - 4 } & & $\mathrm{P}$ & 3 & \\
\hline 4. & MTS Muhammadiyah 1 & $\mathrm{L}$ & 3 & 7 \\
\cline { 3 - 4 } & Pulau Morotai & $\mathrm{P}$ & 4 & \\
\hline & Total & \multicolumn{2}{c}{37} & 37 \\
\hline
\end{tabular}

Keterangan:

JK: Jenis Kelamin

L : Laki-Laki

$\mathrm{P}$ : Perempuan

$\mathrm{Ni}$ : Jumlah sub-sample berdasarkan jenis kelamin

$\mathrm{N}$ : Jumlah sample 
Data observasi juga menunjukkan hasil yang sama dimana terdapat 37 siswa lamban belajar yang tersebar di 4 sekolah Menengah pertama di Kab. Pulau Morotai. Data observasi menggunakan 3 indikator penilaian yakni kognitif, behavior dan emosional. Indikator kognitif mencakup aktivitas; kurang mampu menyimak materi pelajaran yang disajikan gurunya dalam kelas, membutuhkan waktu lama untuk menyelesaikan tugas yang diberikan oleh gurunya, kurang mampu penyimpan huruf dan kata pada ingatannya dalam waktu lama, merasa sulit mengingat-ingat materi yang telah disampaikan oleh guru, kurang mampu membedakan huruf, angka dan suara, tidak sanggup mengikuti penjelasan yang bersifat ganda, memiliki perkembangan akademik yang rendah, kurang mampu bercerita dan sulit membedakan kiri dan kanan, lamban dalam perkembangan berbicara, susah memahami kata dan konsep, kemampuan berbicara terbatas pada satu pokok persoalan.

Indikator behavior mencakup aktifitas; kurang memberi perhatian terhadap tugas-tugas yang diberikan guru, kurang terbiasa melakukan tugas belajar sendiri terutama membaca buku-buku pelajaran, banyak mengajukan keluhan tentang kesulitan mengerjakan tugas, tidak suka menulis dan membaca, sulit akrab dengan orang dan benda, dan indikator emosional meliputi aktifitas tingkah laku yang berubah-ubah setiap hari, suka terdorong oleh perasaan emosional dalam pergaulan, mudah marah dan tersinggung. Data hasil observasi dianalisis secara descriptive untuk mengidentifikasi jumlah siswa lamban belajar.

Berdasarkan data observasi ditemukan bahwa 37 siswa lamban belajar kurang mampu menyimak materi pelajaran yang disajikan gurunya dalam kelas dan sulit mengingat-ingat materi yang telah disampaikan oleh guru. Meskipun materi yang disampaikan oleh guru dilakukan berulang-ulang (3 sampai 4 kali) akan tetapi siswa lamban belajar tidak dapat menangkap materi secara maksimal, bahkan ketika ditanyakan kembali materi yang telah disampaikan, siswa tidak dapat menjawab pertanyaan dengan baik dan benar dan hanya diam. Selain itu siswa lamban belajar membutuhkan waktu lama untuk menyelesaikan tugas yang diberikan oleh gurunya.

Berdasarkan hasil observasi dapat dilihat bahwa siswa lamban belajar tidak dapat menyelesaikan tugas sesuai dengan waktu yang ditentukan oleh guru, sehingga tugas harus dibawah pulang ke rumah dan diselesaikan di rumah atau di luar kelas, bahkan tugas yang dikerjakan tidak pernah mendapatkan skor tinggi dan tidak pernah dapat menyelesaikan tugas dengan sempurna (benar semua), selain itu, tidak adanya ketertarikan siswa untuk mengerjakan tugas yang diberikan oleh gurunya dikarenakan soal-soal latihan yang diberikan oleh guru dianggap terlalu sulit terutama 
untuk tugas yang dikerjakan secara mandiri. Disamping itu, siswa lamban belajar sering mengeluh terhadap sulitnya menyelesaikan tugas-tugas yang diberikan guru, terkadang untuk menghindari tugas-tugas tersebut, siswa lamban belajar memilih tidak masuk sekolah atau bolos mengikuti pelajaran. Temuan lain menunjukkan bahwa siswa lamban belajar sangat tidak tertarik membaca buku-buku pelajaran dikarenakan siswa agak sulit memahami isi bacaan dan tampilan dari buku pelajaran dianggap membosankan dikarenakan buku pelajaran kurang memuat gambar dengan warna yang menarik dan terlalu banyak tulisan. Selain itu, hasil temuan observasi menunjukkan bahwa siswa lamban belajar kurang mampu penyimpan huruf dan kata pada ingatannya.

Pada saat pembelajaran berlangsung siswa lamban belajar sangat sulit mengeja huruf bahkan dalam menulis kata dan cenderung membutuhkan waktu lama untuk berfikir terkait dengan hurufhuruf yang akan ditulis agar menjadi satu kata. Bahkan dalam merangkai sebuah kalimat, siswa lamban belajar membutuhkan pendampingan dari guru mata pelajaran agar dapat menulis dengan baik dan benar. Selain itu, siswa lamban belajar memiliki perkembangan akademik yang rendah, dibuktikan dengan nilai raport pada semua mata pelajaran di semester-semester sebelumnya menunjukkan bahwa rerata siswa lamban belajar tidak memenuhi Kriteria Ketuntasan Minimum (KKM), siswa lamban belajar cenderung di naikkan pada kelas 2 atau 3 hanya sebagai "kenaikan kelas percobaan" bahkan rerata dari ke 37 siswa lamban belajar harus melewati 2 tahun di kelas satu maupun dua.

Hasil lain menunjukkan bahwa siswa lamban belajar kurang mampu bercerita dan lamban dalam perkembangan berbicara, hasil observasi membuktikan bahwa tak jarang siswa lamban belajar cenderung pendiam di dalam kelas, Pada saat berkomunikasi dengan teman sekelas, kalimat yang disampaikan oleh siswa lamban belajar sulit dipahami oleh teman sekelasnya, bahasa yang di gunakan kurang sempurna begitupun sebaliknya ketika guru melakukan komunikasi pada saat proses belajar mengajar berlangsung, siswa lamban belajar lebih sering melihat dengan mulut terbuka (melongo) dan tak jarang menatap ke arah guru tanpa ekspresi, ketika diajukan pertanyaan atau pada saat di ajak berkomunikasi oleh guru mereka lebih memilih diam. Selain itu, hasil lain menunjukkan bahwa siswa lamban belajar susah memahami kata dan konsep, serta kemampuan berbicara terbatas pada satu pokok persoalan. Pada aktifitas emosional, siswa lamban belajar mengalami kesulitan dalam bersosialisasi dengan teman-teman sekelas karena siswa lamban belajar mudah marah dan tersinggung apabila diganggu oleh teman-teman. 


\section{b. Analisis Pola pengajaran yang di Terapkan oleh Guru SMP di Kab Pulau Morotai Terhadap Siswa Lamban Belajar}

Hasil wawancara dan observasi yang dilakukan pada guru mata pelajaran bahasa Inggris di SMP N 2 Pulau Morotai, SMP N 14 Pulau Morotai, MTS N 1 Pulau Morotai, dan MTS Muhammadiyah 1 Pulau Morotai terhadap aktivitas pengajaran yang diterapkan pada siswa lamban belajar, diidentifikasi bahwa guru bahasa Inggris yang mengampu mata pelajaran bahasa Inggris tidak memiliki keahlian khusus/sertifikat keahlian dalam menangani siswa lamban belajar yang bersekolah di sekolah umum. Bahkan sebagian guru bahasa Inggris tidak mengetahui bahwa siswa lamban belajar merupakan siswa yang berkebutuhan khusus.

Dalam penggunaan rancangan pembelajaran selama 1 semester, tidak ada perbedaan RPP dan silabus yang digunakan oleh guru mata pelajaran bahasa Inggris terhadap siswa lamban belajar dengan yang digunakan pada siswa umumnya atau non lamban belajar. Pada saat mengelola ruang kelas, guru membiarkan siswa dengan posisi tempat duduk yang telah ditentukan oleh siswa masing-masing tanpa mengatur letak dan posisi tempat duduk siswa lamban belajar terlebih dahulu, bahkan guru tidak memfasilitasi tempat terpisah untuk siswa lamban belajar dari siswa lainnya.

Sama halnya pada saat proses belajar mengajar berlangsung, soal-soal pembahasan dan soalsoal tes yang diberikan oleh guru memiliki tingkat kesulitan yang sama antara siswa lamban belajar dengan siswa yang memiliki kecerdasan diatas rata-rata, bahkan porsi pemberian soal-soal latihan terhadap siswa lamban belajar tidak ada perbedaan dengan siswa non lamban belajar. Akan tetapi pada saat pembagian tugas kelompok, guru membagi kelompok siswa dengan kemampuan heterogen, dimana siswa lamban belajar di gabung bersama siswa yang memiliki tingkat kecerdasan diatas rata-rata dengan tujuan agar siswa lamban belajar lebih cepat beradaptasi menyelesaikan tugas, dilatih untuk bertanggungjawab, dan berbaur dengan teman sekelas bahkan guru mendorong siswa lainnya untuk membantu.

Temuan lain dilapangan juga menunjukkan bahwa pada saat penyelesaian soal-soal latihan, guru tidak membatasi waktu penyelesaian tugas kepada siswa lamban belajar dibandingkan dengan siswa lainnya. Setiap siswa lamban belajar yang tidak dapat menyelesaikan soal-soal latihan tepat waktu, guru menginstruksikan untuk diselesaikan di rumah dan dikumpulkan pada esok harinya di sekolah. Pada saat menjelaskan materi, guru jarang memanggil nama siswa lamban belajar agar memperhatikan materi yang disampaikan, guru menjelaskan materi secara lambat dan berulang- 
ulang 2-3 kali dan memberikan contoh dengan peragaan/ gesture agar mudah dipahami, meskipun beberapa siswa lamban belajar cenderung meminta untuk dijelaskan lebih detail, akan tetapi terkadang guru tidak dapat menyanggupinya.

Hal ini dikarenakan keterbatasan waktu dimana waktu mengajar disesuaikan dengan RPP dan Silabus serta guru mata pelajaran sering menuai protes dari siswa lainnya apabila materi yang dijelaskan terlalu sering diulang $(5 \mathrm{x})$ sehingga siswa merasa bosan dengan pelajaran tersebut. Untuk memastikan tingkat pemahaman yang ditangkap oleh siswa lamban belajar, setiap selesai menjelaskan, guru mencoba bertanya secara langsung kepada siswa lamban belajar. Dalam menggunakan media pembelajaran pada saat proses belajar mengajar berlangsung, guru hanya menggunakan media pembelajaran seperti buku pelajaran dan latihan soal-soal.

Jarangnya penggunaan alat peraga, demonstrasi visual, maupun alat bantu memori/memory aid sehingga siswa lamban belajar mengalami kesulitan dalam mengingat materi yang disampaikan. Metode maupun teknik pengajaran yang digunakan terkesan sangat monoton yaitu terlalu sering menggunakan metode ceramah sehingga terkesan pembelajaran berpusat pada guru semata dan jarang menerapkan maupun melakukan kolaborasi metode/teknik pembelajaran selama proses belajar mengajar di dalam kelas berlangsung. Begitupun pada saat pemberian materi yang berupa teks-teks bacaan guru tidak menandai teks-teks tertentu seperti tajuk bacaan, kalimat, kata kunci, bahkan guru tidak memberikan high-lighting/menggaris-bawahi kata-kata tertentu dalam teks yang bertujuan untuk mempermudah siswa lamban belajar mengingat materi.

Setelah jam pembelajaran selesai, guru tidak pernah memberikan tambahan jam pelajaran di luar jam pelajaran efektif dan tidak mempersilahkan ke luar kelas untuk mendapatkan remedi dari guru pembimbing khusus (GBK) dikarenakan tidak tersedianya GBK yang menangani anak berkebutuhan khusus di sekolah-sekolah SMP di Kabupaten Pulau Morotai. Akan tetapi pada akhir semester guru selalu meminta orang tua agar lebih memperhatikan belajar putra/putrinya serta menyampaikan kendala-kendala yang dihadapi anak-anak mereka pada saat proses pembelajaran di dalam kelas.

Berdasarkan hasil analisis terhadap pola pengajaran yang di terapkan oleh guru SMP di Kab Pulau Morotai pada siswa lamban belajar dapat disimpulkan bahwa hak siswa lamban belajar untuk memperoleh pendidikan yang layak belum sepenuhnya terpenuhi baik pada komponen tujuan, metode, strategi, maupun media. Padahal dapat dilihat bahwa, tujuan dari inklusi adalah sebuah 
keharusan untuk memenuhi hak dan martabat bagi penyandang disabilities sebagaimana tercantum dalam Undang-Undang Repuplik Indonesia Nomor 19 tahun 2011 tentang Konvensi Hak-hak Penyandang Disabilities. Hal penting yang perlu diperhatikan untuk menangani siswa lamban belajar yang bersekolah di sekolah umum yakni perancangan kurikulum pendidikan. Kurikulum pendidikan perlu beradaptasi dan melakukan penyesuaian pada beberapa aspek program pembelajaran guna memenuhi kebutuhan belajar siswa lamban belajar (Mumpuniarti, 2011; 12).

Menurut Yoshini (2014: 111) Anak yang tergolong pada kategori beorderline yang mengalami learning difficulties atau yang dikenal dengan slow learners sangat memerlukan pendidikan serta layanan khusus yang berbeda dengan anak-anak pada umumnya. Salah satu layanan pendidikan yang dapat disediakan adalah kelas terpadu yang diselenggarakan di sekolah regular. Siswa lamban belajar dapat belajar bersama-sama dengan anak reguler di kelas yang sama dengan bimbingan guru reguler. Kesulitan yang dihadapi siswa lamban belajar untuk mata pelajaran tertentu dapat diatasi dengan bimbingan/ remedial dari Guru Pembimbing Khusus (GPK) dari SLB terdekat, pada ruang khusus atau ruang sumber.

Bahkan Palupi dan Darmahusni (2017: 81) Menambahkan bahwa siswa lamban belajar tidak perlu berada dalam sistem pendidikan khusus akan tetapi perlakuan pembelajaran yang diberikan harus disesuaikan dengan kemampuan siswa, dimana penyesuaian meliputi berbagai komponen baik tujuan, metode, strategi, maupun media. Sejalan dengan apa yang diungkapkan oleh Husain dan Ibrahim (2018: 104) Salah satu karakteristik penting dari pembelajaran yang efektif adalah ketika proses pembelajaran tersebut mampu merespon kebutuhan individual siswa, dengan demikian pembelajaran memerlukan sensitifitas terhadap perbedaan individual. Guru dapat membuat variasi metode, strategi, teknik maupun media dalam proses pembelajaran. Guru yang dapat mengakomodasi kebutuhan individual menunjukkan bahwa mereka ingin merangkul seluruh siswa dalam seluruh proses pembelajaran.

Faktor guru dan cara mengajarnya merupakan salah satu factor pendukung agar pembelajaran dapat berhasil. Bagaimana sikap dan kepribadian guru, tinggi rendahnya wawasan yang dimiliki guru dan bagaimana cara mentransfer ilmu pengetahuan kepada siswa turut menentukan prestasi akademik yang diraih siswa tersebut (Amin dan Suardiman, 2016:13). 


\section{SIMPULAN DAN SARAN}

Kebutuhan siswa lamban belajar yang menempuh pendidikan di sekolah umum belum sepenuhnya terpenuhi dan belum mendapatkan perhatian serius dari pelaku pendidikan. Belum adanya adaptasi kurikulum yang menyesuaikan dengan kebutuhan siswa lamban belajar sehingga kebutuhan siswa lamban belajar tidak terakomodasi dengan baik. penggunaan kurikulum di sekolah umum untuk siswa lamban belajar membutuhkan beberapa penyesuaian beberapa aspek program pembelajaran. Aspek program pembelajaran mencakup cara penyajian, cara respon siswa, keterlibatannya dalam belajar serta penambahan strategi, metode maupun teknik pembelajaran.

Hasil penelitian ini diharapkan menjadi bahan masukan terhadap para guru di Kabupaten Pulau Morotai serda Dinas Pendidikan setempat. Perlu adanya perhatian khusus pada siswa lamban belajar (slow learners) yang bersekolah di sekolah formal pada umumnya. Selain itu, perlu adanya teknik/metode pengajaran bahkan pengelolaan kelas yang efektif dikhususkan pada siswa lamban belajar agar siswa lamban belajar memiliki fokus belajar yang tinggi. Bagi para guru-guru di Kab Pulau Morotai perlu mendapatkan peelatihan serta memiliki keahlian khusus dalam mengajar siswasiswa lamban belajar yang bersekolah di sekolah formal pada umumnya.

\section{REFERENSI}

Amin, Alima dan Suardiman, P. Siti. 2016. Perbedaan Prestasi Belajar Matematika Siswa Ditinjau dari Gaya Belajar dan Model Pembelajaran. Jurnal Prima Edukasia Vol 4 No,1 Januari 2016. Yogyakarta: Universitas Ahmad Dahlan.

Bala, Jampala Madhu \& Rao, Digurmati Bhaskara.2004. Methods of Teaching Exceptional Children. New Dehli: Discovery Publishing House.

Chauchan, Sangeeta. 2011. Slow Learner; Their Psychology and Educational Programmmes. Zenith International Journal of Multidisciplinary Research. Vol 1 Issued 8 Desember 2011.

Husain, B., \& Ibrahim, I. 2018. Perbedaan Prestasi Belajar Ditinjau dari Kepribadian Introvert dan Extrovert. Qalam: Jurnal Ilmu Kependidikan. Vol 7 No 2. doi: https://doi.org/10.33506/jq.v7i2.371

Mumpuniarti, Rudiyati Sari \& Cahyaningrum, Eka Sapti. 2011. Kebutuhan Belajar Siswa Lamban Belajar (Slow- Learner) di Kelas Awal Sekolah Dasar Daerah Istimewa Yogyakarta. Artikel Penelitian. Pendidikan Luar Biasa. Fakultas Ilmu Pendidikan. Universitas Negeri Yogyakarta.

Palupi, Dian dan Darmahusni. 2017. Pembelajaran Menulis Deskriptif Bahasa Inggris di Kelas X pada Siswa Lamban Belajar (Suatu Kajian Etnografi di Sekolah Budiwaluyo, Jakarta). Jurnal Pendidikan Bahasa dan Sastra Vol. 16 No 2 Juli 2017. ISSN 0853-2710 (http://journal.unj.ac.id/unj/index.php/bahtera/ 
Sari, Ninuk Wahyunita \& Samawi, Ahmad. 2014. Pengaruh Penggunaan Media Animasi terhadap Hasil Belajar IPA Siswa Slow Learner. Jurnal Penelitian dan Pengembangan Pendidikan Luar Biasa. Vol 1 no 22014 (140-144). Universitas Negeri Malang.

Yosiani, Novita. 2014. Relasi Karakteristik Anak Tunagrahita dengan Pola Tata Ruang Belajar Di Sekolah Luar Biasa. E-Journal Graduate Unpar Part D - Architecture Vol. 1, No. 2. (111124). Universitas Katolik Parahyangan. 